\title{
Vagal Regulation of Insulin, Glucagon, and Somatostatin Secretion In Vitro in the Rat
}

Shigeo Nishi, Yutaka Seino, Hitoshi Ishida, Michiyo Seno, Tomohiko Taminato, Hideo Sakurai, and Hiroo Imura Second Division, Department of Medicine, Kyoto University School of Medicine; and Department of Metabolism and Clinical Nutrition, Kyoto University School of Medicine, Kyoto, 606 Japan

\begin{abstract}
Using a new in vitro procedure of the isolated perfused rat pancreas with vagal innervation, electrical vagal stimulation produced an increase in both insulin and glucagon secretion in proportion to the pulse frequency, but an inhibition in somatostatin release. When atropine was infused, both insulin and glucagon responses to vagal stimulation were partially suppressed, whereas somatostatin release was enhanced. In the presence of hexamethonium, vagal stimulation failed to affect insulin, glucagon, or somatostatin secretion. Propranolol partially blocked both insulin and glucagon responses but did not influence somatostatin response. Phentolamine had no significant effect on release of hormones. Simultaneous administration of propranolol and phentolamine tended to inhibit both insulin and glucagon responses to vagal stimulation. These findings suggest that not only a cholinergic but also a noncholinergic neuron may be involved in vagal regulation of pancreatic hormone secretion and that these neurons may be under the control of preganglionic vagal fibers via nicotinic receptors.
\end{abstract}

\section{Introduction}

It is known that the pancreatic islets are well innervated with the autonomic nervous system in various species $(1,2)$. Recent studies have demonstrated that electrical stimulation of the vagus nerve elicits insulin and/or glucagon release (3-5). It has been shown also in in vivo studies that electrical vagal stimulation causes an increase in the blood glucose level $(6,7)$ and enhances the release of gastrin (8) and vasoactive intestinal polypeptide $(\mathrm{VIP})^{1}(9)$. These extrapancreatic factors are known to influence pancreatic endocrine functions and make it difficult to evaluate the direct vagal effect on the pancreas although previous studies elaborated procedures to obviate indirect effect as much as possible (10-12). On the other hand, the role of the vagus nerve in regulating somatostatin secretion from the pancreas has not been well studied. To our knowledge, there has been only a report (13) demonstrating an inhibition by vagal stimulation of somatostatin secretion from the isolated perfused pig pancreas

Address reprint requests to Dr. Nishi, 2nd Division, Department of Internal Medicine, Kyoto University School of Medicine, 54 Sakyo-ku, Shogoin Kawara-cho, Kyoto 606, Japan.

Received for publication 21 February 1986 and in revised form 30 October 1986

1. Abbreviations used in this paper: $\mathrm{CCK}$, cholecystokinin; VIP, vasoactive intestinal polypeptide.

J. Clin. Invest.

(C) The American Society for Clinical Investigation, Inc.

0021-9738/87/04/1191/06 \$1.00

Volume 79, April 1987, 1191-1196 prepared with an intact vagal supply. We have developed a new in vitro method in which the rat pancreas was isolated with intact vagus nerve fibers and perfused. Using this procedure, we have investigated the effects of vagal stimulation on insulin, glucagon, and somatostatin secretion. Furthermore, since vagus nerves is shown to contain not only cholinergic fibers but also adrenergic fibers $(14,15)$, we have studied the effects of cholinergic and adrenergic blockers on insulin, glucagon, and somatostatin responses to vagal stimulation.

\section{Methods}

Male Wistar rats weighing 230-280 g were housed at least $1 \mathrm{wk}$ before the experiment in a temperature and light conditioned room and fasted overnight before the experiment. Anesthesia was induced by intraperitoneal administration of $6 \mathrm{mg} / 100 \mathrm{~g}$ body wt sodium pentobarbital. The pancreas was isolated as previously described (16), with some modifcations. Briefly, laparotomy was performed and the omentum connecting the pancreas to the transverse colon was severed. The superior and inferior mesenteric arteries and veins were ligated and cut. The intestine below the duodenum was then removed from the rat. The splenic arteries near the splenic hilus, the right and left gastric arteries, and the gastric branches of the gastroepiploic artery were ligated individually. The abdominal aorta was carefully separated from the connective tissue and an arterial cannula was inserted into the celiac artery while paying attention not to damage the celiac plexus. The portal vein was then cannulated. In almost all rats, the pancreatic duct was cannulated nearly proximal to the duodenal papilla and ligated at the level of the hepatic hilus. The pancreatic juice was collected into capillary tubes every $5 \mathrm{~min}$ and frozen. The completeness of the electrical vagal stimulation was confirmed by checking the increase in pancreatic fluid flow. The vagus nerves were isolated and cut beneath the diaphragm. Then, the vagus nerve fibers, pancreas, spleen, stomach, duodenum, liver, and a lower part of the esophagus were removed in one block from the rat and placed into a temperature and humidity conditioned perfusion chamber. A bipolar platinum electrode was placed on the peripheral ends of the subdiaphragmatic vagal trunks and the nerves were stimulated by $1 \mathrm{~ms}, 10 \mathrm{~V}$ square-wave impulses at frequencies from 2 to $10 \mathrm{~Hz}$. A dye distribution study in several perfusion preparations showed that only the pancreas and duodenum were perfused and that other organs attached to the pancreas were excluded from the perfusion (Fig. 1). Although some branches of the vagus nerves coursing over the unperfused stomach were not bathed with oxygenated buffer, celiac branches entering the perfused pancreas immediately after they are derived from the subdiaphragmatic vagal trunk were bathed with buffer. In some experiments, 5 min vagal stimulations were repeated every 30 min over a 180 -min period and almost identical increases in pancreatic fluid flow were found after each vagal stimulation, suggesting that the vagus nerves survive this procedure for a period sufficient to the experiment.

All perfusions were accomplished with Krebs-Ringer bicarbonate buffer containing $0.25 \%$ bovine serum albumin and $4.6 \%$ dextran (mean mol wt 70,000). The medium was gassed with $95 \% \mathrm{O}_{2}$ and $5 \% \mathrm{CO}_{2}$ and maintained at $\mathrm{pH} 7.4$ at $37^{\circ} \mathrm{C}$. The perfusion rate was kept constant at $1.9 \mathrm{ml} / \mathrm{min}$ throughout the experiment. Each 1-min effluent from the portal vein was collected in chilled tubes containing 1,000 $\mathrm{U}$ of Trasylol, frozen immediately, and stored at $-20^{\circ} \mathrm{C}$ until assayed. 


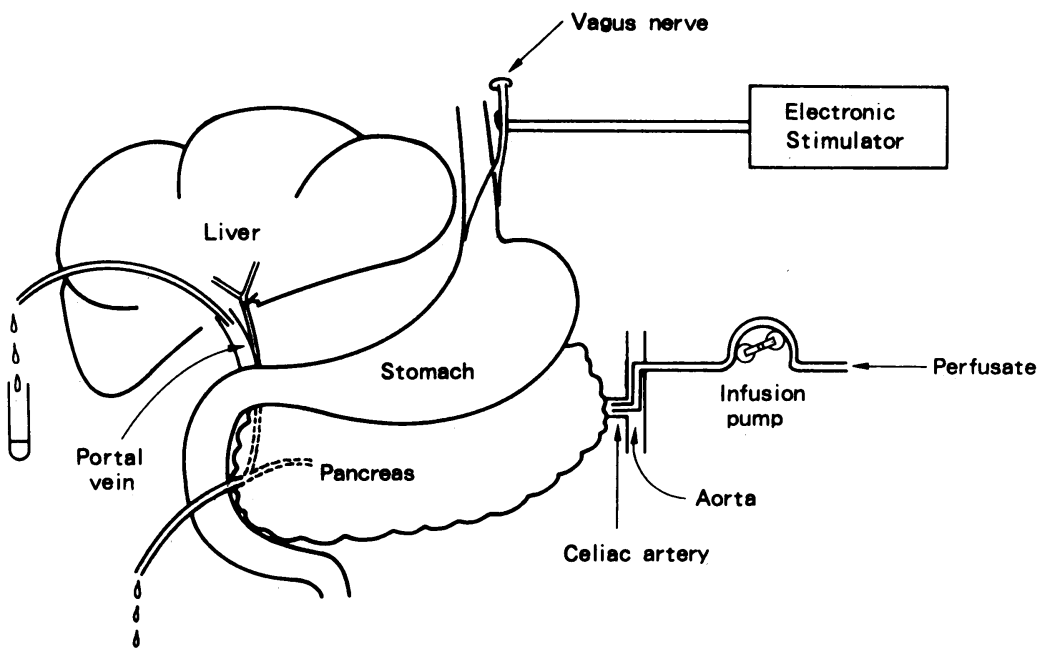

Figure 1. Schematic representation of the isolated perfused rat pancreas preparation with vagus nerve fibers.

\section{Experimental protocol}

Experiment $I$. After an equilibration period of $20 \mathrm{~min}$, samples were taken for $30 \mathrm{~min}$. The glucose concentration was kept constant at 5.5 $\mathrm{mM}$ throughout the experiment. $3 \mathrm{~min}$ after the start of sampling, the first electrical stimulation of the vagus nerves was applied for $5 \mathrm{~min}$. The second stimulation was carried out $15 \mathrm{~min}$ after the end of the first stimulation with a duration of $5 \mathrm{~min}$. Both electrical stimulations were performed at 2,5 , and $10 \mathrm{~Hz}(10 \mathrm{~V}, 1 \mathrm{~ms}$ pulse)

Experiment II. Infusion of the perfusate containing $5.5 \mathrm{mM}$ glucose was continued during the whole experiment. As in the experiment $I$, the first electrical stimulation of the vagus nerves was applied at $10 \mathrm{~Hz}(10$ $\mathrm{V}, 1 \mathrm{~ms}$ pulse) and the second one after an interval of $15 \mathrm{~min}$. In order to investigate the effect of a muscarinic cholinergic, a ganglionic, an adrenergic, or an opiate receptor antagonist on vagally induced hormone release, a final concentration of $10^{-5}$ or $10^{-7} \mathrm{M}$ atropine sulfate, $10^{-4} \mathrm{M}$ hexamethonium bromide, $10^{-6} \mathrm{M}$ DL-propranolol hydrochloride, $10^{-6}$ $M$ phentolamine mesylate (all from Nakarai Chemicals, Kyoto, Japan), $10^{-6} \mathrm{M}$ propranolol plus $10^{-6} \mathrm{M}$ phentolamine, or $10^{-6} \mathrm{M}$ naloxone hydrochloride (Sankyo Co., Ltd., Tokyo, Japan) was infused over a period of 13 min starting 6 min before the beginning of the second vagal stimulation.

Radioimmunoassay. Insulin was measured by the polyethylene glycol method (17) and glucagon was determined by the talcum adsorption radioimmunoassay of Sakurai et al. (18), using an antiserum OAL 123 (Otsuka Assay Laboratory, Tokushima, Japan) specific for pancreatic glucagon (19). Immunoreactive somatostatin was measured by a specific radioimmunoassay (16), with a modification of the method described by Arimura et al. (20), using an antiserum T-316. This antiserum did not cross-react with insulin, glucagon, gastrin, motilin, VIP, secretin, and substance $P$.

\section{Statistical analysis}

Statistical analyses were performed by two-way analysis of variance, followed by Duncan's multiple range test (21) if null hypotheses were rejected by the former.

\section{Results}

Effects of electrical stimulation of the vagus nerves on insulin, glucagon, and somatostatin secretion. As shown in Fig. 2, the first electrical stimulation $(10 \mathrm{~Hz}, 1 \mathrm{~ms}$ pulse, $10 \mathrm{~V})$ of the peripheral ends of the subdiaphragmatic vagal trunks elicited an abrupt increase in insulin from the basal level of $0.28 \pm 0.05 \mathrm{ng} /$ $\mathrm{ml}($ mean $\pm \mathrm{SE})$ to a peak level of $2.43 \pm 0.51 \mathrm{ng} / \mathrm{ml}(P<0.01)$. Glucagon secretion was also significantly stimulated by the first vagal stimulation, rising from the basal value of $57.7 \pm 6.7 \mathrm{pg} /$ $\mathrm{ml}$ to a peak value of $169.1 \pm 29.8 \mathrm{pg} / \mathrm{ml}(P<0.01)$. Both the insulin and glucagon responses to the second vagal stimulation tended to be more intense than the first ones, although the difference was not statistically significant (Fig. 2). Furthermore, the peak values of insulin and glucagon in response to both the first and second vagal stimulations were dependent upon the frequency of the stimuli, the maximum response being obtained at $10 \mathrm{~Hz}$ so far as we studied. On the other hand, somatostatin secretion was significantly decreased by vagal stimulation $(10$ $\mathrm{Hz}, 1 \mathrm{~ms}, 10 \mathrm{~V})$, from $40.1 \pm 4.8 \mathrm{pg} / \mathrm{ml}$ to $25.1 \pm 2.4 \mathrm{pg} / \mathrm{ml}(P$ $<0.05)$.

Effects of atropine on insulin, glucagon, and somatostatin responses to vagal stimulation. The infusion of $10^{-5}$ or $10^{-7} \mathrm{M}$ atropine did not influence basal levels of insulin, glucagon, or somatostatin (Fig. 3). Electrical vagal stimulation during the infusion of $10^{-5} \mathrm{M}$ atropine elicited significant but lesser increases in insulin and glucagon from mean basal values of $0.19 \pm 0.02$ $\mathrm{ng} / \mathrm{ml}$ and $26.9 \pm 3.2 \mathrm{pg} / \mathrm{ml}$ to peak values of $0.49 \pm 0.1 \mathrm{ng} / \mathrm{ml}$ and $64.6 \pm 9.7 \mathrm{pg} / \mathrm{ml}$, respectively. The peak values of insulin and glucagon were significantly lower than those achieved in the absence of atropine, which were $1.53 \pm 0.22 \mathrm{ng} / \mathrm{ml}$ and $128.4 \pm 16.6 \mathrm{pg} / \mathrm{ml}$, respectively $(P<0.05, P<0.05)$ (Fig. $3, a$ and $b$ ). In contrast, somatostatin secretion in response to vagal stimulation, which was suppressed without atropine was reversed in the presence of $10^{-5} \mathrm{M}$ atropine: the mean basal value of $27.4 \pm 4.5 \mathrm{pg} / \mathrm{ml}$ rose to a peak value of $105.3 \pm 49.3 \mathrm{pg} / \mathrm{ml}$ in response to stimulation $(P<0.05)$ (Fig. $3 c$ ). There were no significant differences in the responses of insulin, glucagon, and somatostatin to vagal stimulation between $10^{-7}$ and $10^{-5} \mathrm{M}$ atropine (Fig. 3).

Effects of hexamethonium on insulin, glucagon, and somatostatin responses to vagal stimulation. As shown in Fig. $4,10^{-4}$ $\mathbf{M}$ hexamethonium did not change the basal releases of insulin, glucagon, or somatostatin. The responses of all these hormones to vagal stimulation were completely abolished in the presence of hexamethonium.

Effects of propranolol on insulin, glucagon, and somatostatin responses to vagal stimulation. Basal secretions of insulin, glucagon, and somatostatin were not affected by the infusion of $10^{-6} \mathrm{M}$ propranolol (Fig. 5). The peak levels of insulin and glucagon in response to vagal stimulation were $0.59 \pm 0.12 \mathrm{ng} / \mathrm{ml}$ and $104.3 \pm 38.3 \mathrm{pg} / \mathrm{ml}$, respectively, being significantly lower 


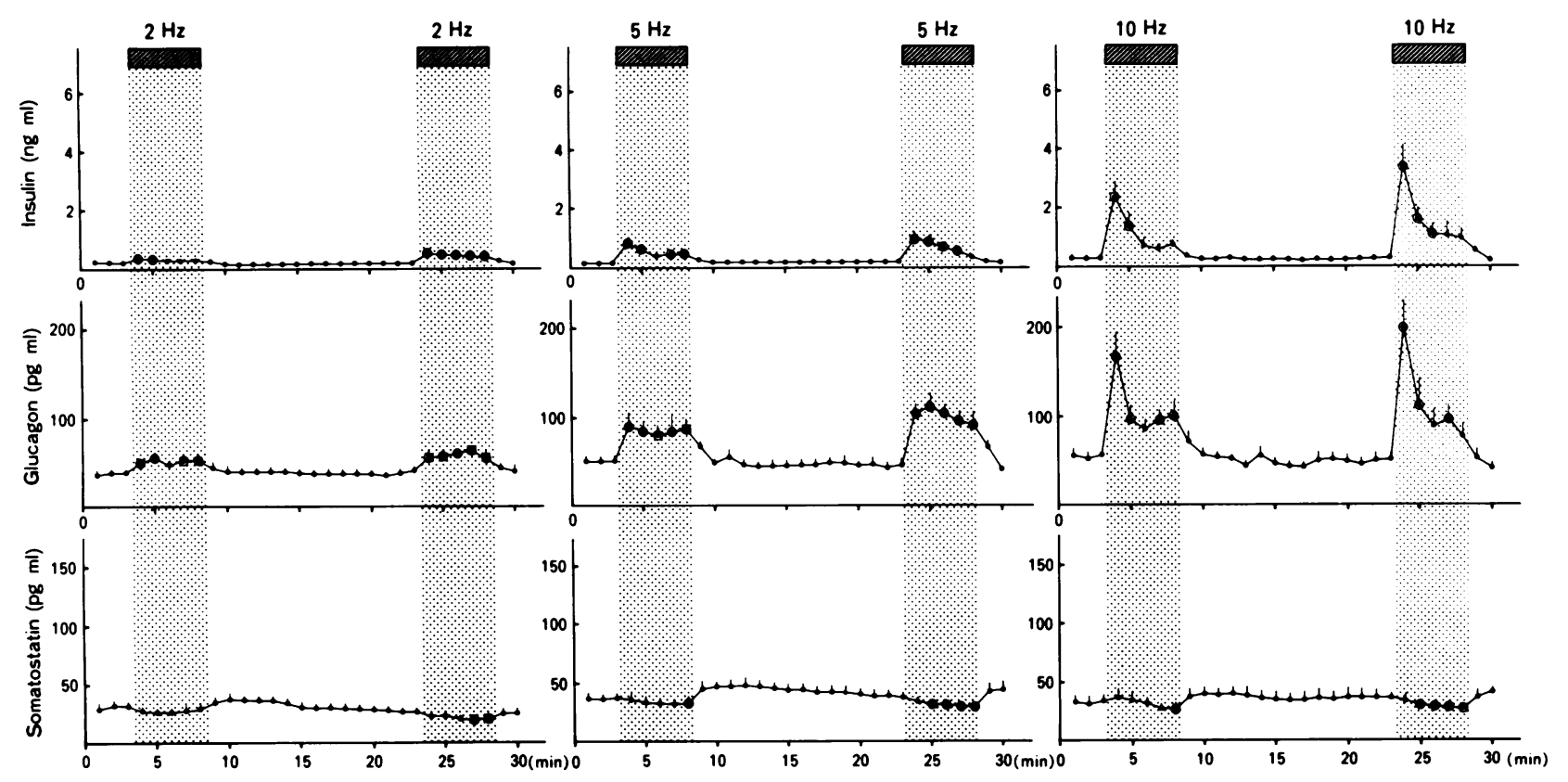

Figure 2. Effects of electrical vagal stimulation at various pulse frequencies $(2-10 \mathrm{~Hz})$ on insulin, glucagon and somatostatin secretion from isolated perfused rat pancreas. Means $( \pm \mathrm{SE})$ of eight individual experiments are shown. $\odot$ indicates significant differences $(P<0.05$ or less $)$ compared to baseline levels prior to each vagal stimulation.

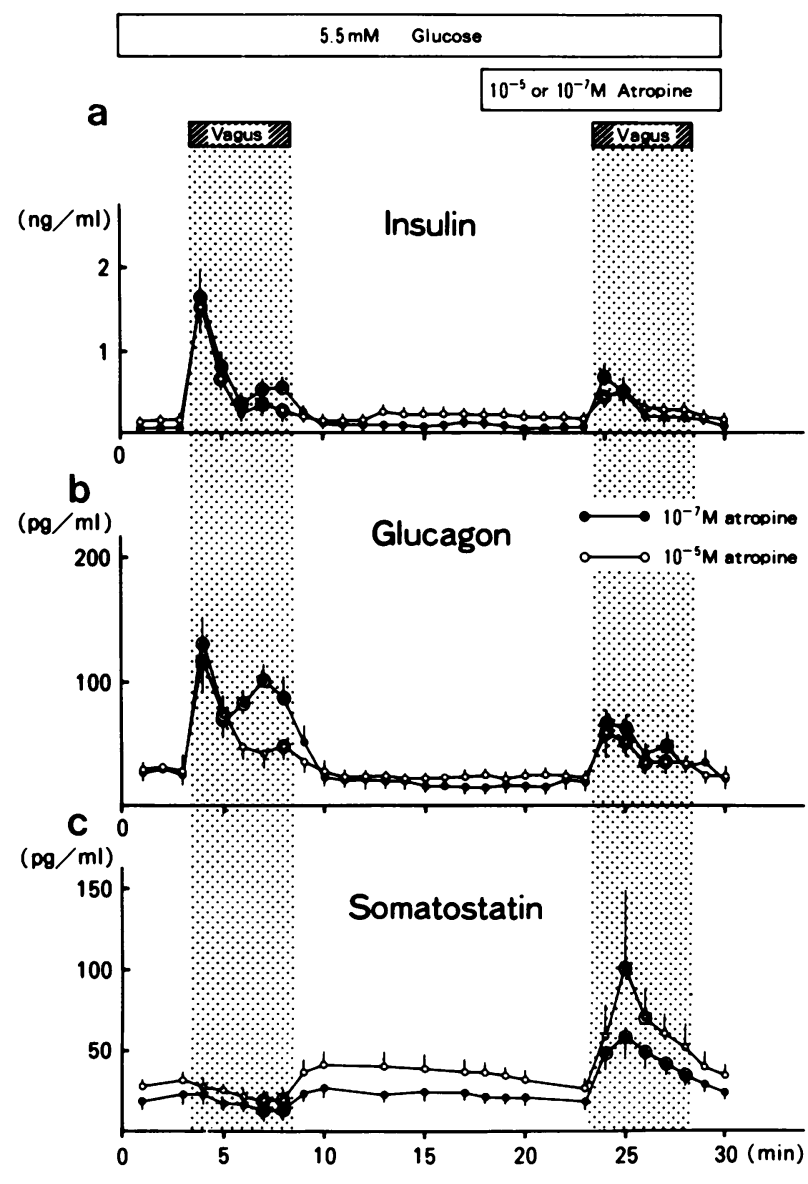

Figure 3. Effects of electrical vagal stimulation with and without $10^{-5}$ or $10^{-7} \mathrm{M}$ atropine on releases of insulin, glucagon and somatostatin from isolated perfused rat pancreas. Means $( \pm \mathrm{SE})$ of seven individual experiments are shown. $\odot$ and $\odot$ indicate significant differences $(P$ $<0.05$ or less) compared to baseline levels before each vagal stimulation.

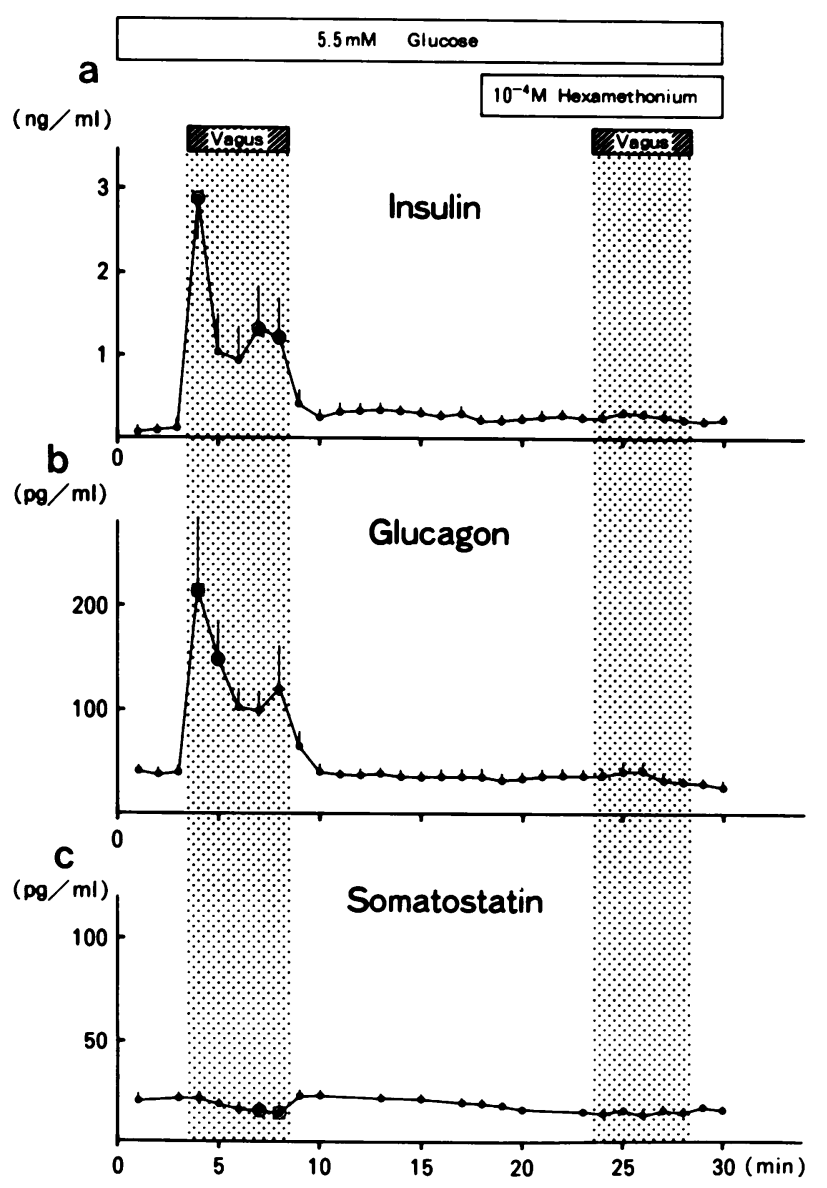

Figure 4. Effects of electrical vagal stimulation with and without $10^{-5}$ $M$ hexamethonium on releases of insulin, glucagon and somatostatin from isolated perfused rat pancreas. Mean values ( \pm SE) of six individual experiments are shown. $\odot$ indicates significant differences $(P$ $<0.05$ or less) compared to baseline levels prior to each vagal stimulation. 


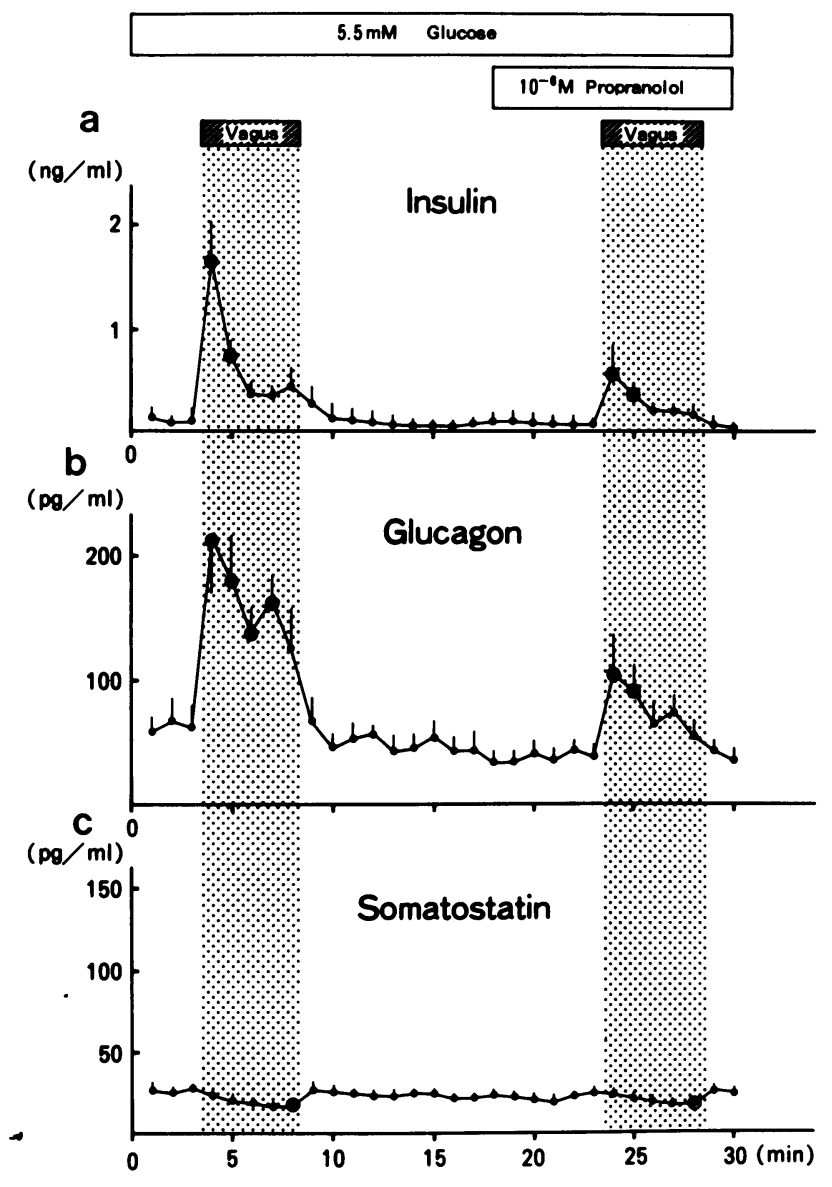

Figure 5. Effects of electrical vagal stimulation with and without $10^{-6}$ $M$ propranolol on releases of insulin, glucagon and somatostatin from isolated perfused rat pancreas. Mean values $( \pm \mathrm{SE})$ of six individual experiments are shown. $\odot$ indicates significant differences $(P<0.05$ or less) compared to baseline levels prior to each vagal stimulation.

than the corresponding peak values of insulin and glucagon in the absence of propranolol, $1.65 \pm 0.41 \mathrm{ng} / \mathrm{ml}$ and $214.4 \pm 42.9$ $\mathrm{pg} / \mathrm{ml}$, respectively $(P<0.05, P<0.05)$ (Fig. $5, a$ and $b)$. On the other hand, propranolol at a concentration of $10^{-6} \mathrm{M}$ did not affect the inhibitory effect of vagal stimulation on somatostatin secretion (Fig. 5 c).

Effects of phentolamine on insulin, glucagon, and somatostatin responses to vagal stimulation. The infusion of $10^{-6} \mathrm{M}$ phentolamine did not influence basal insulin, glucagon, and somatostatin secretion (Fig. 6). The insulin and glucagon responses to vagal stimulation were not affected by phentolamine (Fig. 6 , $a$ and $b$ ). The somatostatin inhibition by vagal stimulation was also not affected by phentolamine (Fig. $6 c$ ).

Combined effects of propranolol and phentolamine on insulin, glucagon, and somatostatin responses to vagal stimulation. The simultaneous administration of $10^{-6} \mathrm{M}$ propranolol and $10^{-6}$ $M$ phentolamine tended to inhibit both insulin and glucagon responses to vagal stimulation although somatostatin response was not affected significantly by this treatment (Fig. 7).

\section{Discussion}

We have established a new in vitro procedure which enables us to study the direct effect of electrical vagal stimulation on pancreatic endocrine function. Using this rat pancreas perfusion

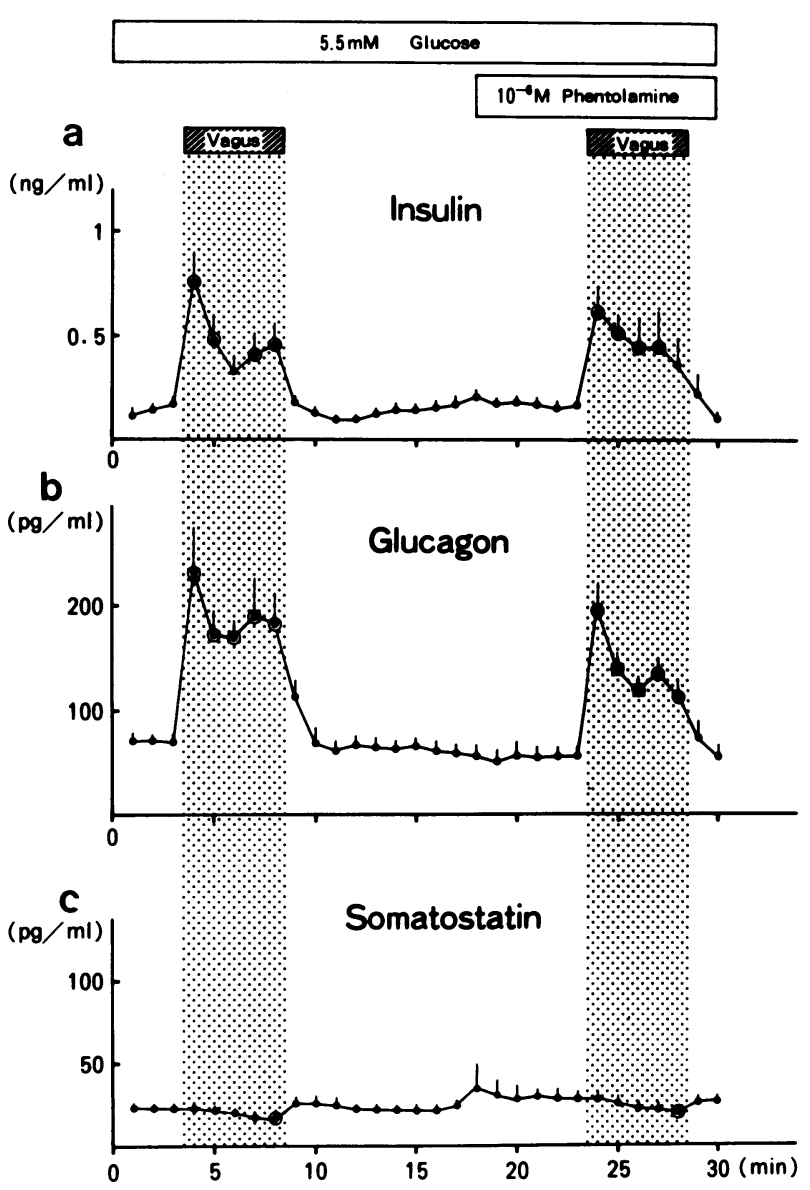

Figure 6. Effects of electrical vagal stimulation with and without $10^{-6}$ $M$ phentolamine on releases of insulin, glucagon, and somatostatin from isolated perfused rat pancreas. Mean values $( \pm \mathrm{SE})$ of six individual experiments are shown.

technique, we have demonstrated that electrical stimulation of the vagus nerves elicits the release of both insulin and glucagon in proportion to the pulse frequency. Uvnäs-Wallensten et al. (22) have shown a constant relationship between the amount of insulin released and the number of electrical impulses applied to the vagus in anesthetized cats. Holst et al. (23) have found also, in pigs, that increases in insulin and pancreatic glucagon concentrations in the portal vein and arterial plasma in response to electrical stimulation of the vagus nerve are frequency-dependent: the threshold frequency was below $1 \mathrm{~Hz}$ and the maximum response achieved at 8-12 $\mathrm{Hz}$. It appears, therefore, that vagal stimulation of insulin and glucagon secretion is a shared phenomenon observed in different species. A characteristic feature of the present experiment is an in vitro method that minimizes the intervention of gastrointestinal and circulating factors. Under such condition, the electrical vagal stimulation attained a peak insulin value within $2 \mathrm{~min}$, followed by a rapid fall, despite the persistence of stimulation. Such a secretory pattern has been commonly recognized in previous in vivo experiments $(7,10)$. In order to elucidate neurotransmitter mechanisms in the vagal regulation of pancreatic hormone secretion, we first studied the effect of anticholinergic agents. Atropine, a muscarinic antagonist, at concentrations of $10^{-7} \mathrm{M}$ and $10^{-5} \mathrm{M}$, significantly lowered insulin and glucagon responses to vagal stimulation, but failed to abolish them. On the other hand, hexamethonium, 


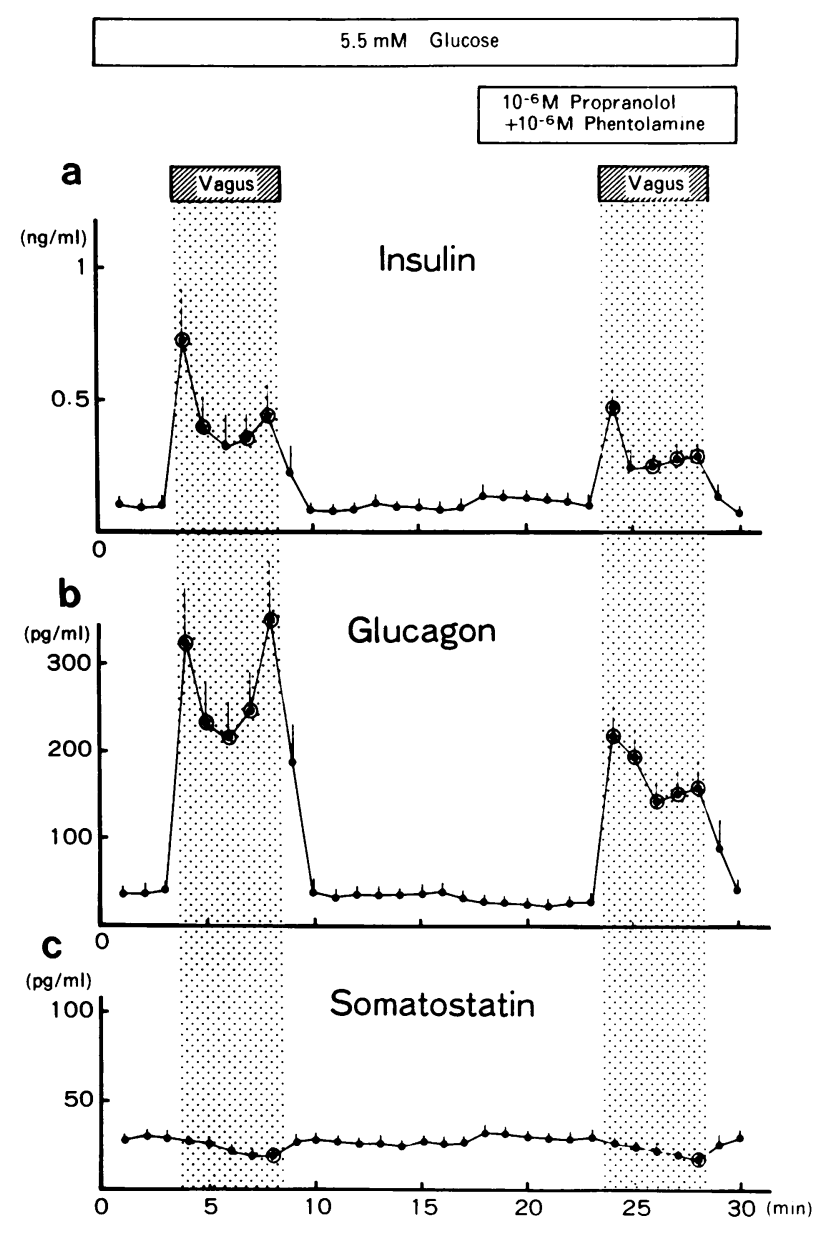

Figure 7. Effects of electrical vagal stimulation with and without both propranolol and phentolamine on releases of insulin, glucagon, and somatostatin from isolated perfused rat pancreas. Mean values $( \pm \mathrm{SE})$ of six individual experiments are shown.

a ganglionic nicotinic blocker, completely abolished the effects of vagal stimulation. These results suggest that, in addition to cholinergic neurons, there exist noncholinergic neurons that mediate the vagal stimulation of insulin and glucagon secretion and that these neurons are under the control of preganglionic fibers via ganglionic nicotinic receptors.

Since previous studies have demonstrated that the vagus nerves contain adrenergic fibers $(14,15)$, it might be possible that adrenergic fibers in the vagus nerve contribute to insulin and glucagon secretion induced by vagal stimulation. In the present study, we then studied the effect of adrenergic blocking agents. A $\beta$-adrenergic antagonist, propranolol, partially inhibited the insulin and glucagon responses to vagal stimulation, although it did not affect basal releases of these hormones. On the other hand, an $\alpha$-adrenergic antagonist, phentolamine, had no significant effect. In addition, the combined administration of propranolol and phentolamine failed to affect insulin and glucagon responses to vagal stimulation. It seems unlikely, therefore, that an adrenergic fiber plays an important role in the regulation of vagally induced pancreatic hormone secretion. Since propranolol is known to blunt insulin and glucagon secretion induced by a variety of stimuli (3-5), the effect of propranolol may be mediated by the mechanism other than adrenergic system. The significance of inhibitory effect of propranolol on vagal stimulation of insulin and glucagon secretion must be studied further.
Other neurons possibly involved in insulin and glucagon secretion are peptidergic neurons. Various peptides such as VIP (24), the C-terminal tetrapeptide of cholecystokinin (CCK) (25), neurotensin (26), substance P (27), and enkephalin (28), all of which are known to stimulate insulin and/or glucagon secretion, have been found in nerve fibers and ganglion cells of the feline pancreas (29). It is possible, therefore, that some peptidergic neurons are partly responsible for insulin and glucagon secretion induced by vagal stimulation.

The effect of vagal stimulation on pancreatic somatostatin release is still not well known. A recent study in pigs has shown that electrical vagal stimulation inhibits the somatostatin release which is reversed in the presence of atropine and suggested that a cholinergic neuron has an inhibitory effect on pancreatic somatostatin secretion (13). In the present in vitro study, vagal stimulation produced an inhibition in pancreatic somatostatin release. In the presence of atropine, however, somatostatin was rather increased by electrical stimulation of the vagus nerves, whereas hexamethonium completely abolished the somatostatin response to vagal stimulation. A possible explanation of these findings might be that pancreatic somatostatin may be regulated not only by a cholinergic inhibitory neuron, but also by an atropine-resistant noncholinergic neuron or neurons that directly stimulate somatostatin release. This is in accordance with our previous findings (30) that somatostatin secretion from the isolated perfused rat stomach is inhibited by electrical vagal stimulation but that it was rather increased in the presence of atropine. The present study showed that neither $\alpha$-nor $\beta$-adrenergic blocker influenced vagal effects on pancreatic somatostatin secretion. It is still not known, therefore, what neurons are involved in vagal regulation of somatostatin secretion. Further studies are required to answer the question.

\section{Acknowledgments}

We wish to thank $\mathrm{H}$. Tachikawa and M. Ohno for their skilled technical assistance.

This work was supported in part by a Grant-in-Aid for Developmental Scientific Research from the Ministry of Education, Science and Culture (No. 60570529).

\section{References}

1. Coupland, R. E. 1958. The innervation of pancreas of the rat, cat and rabbit as revealed by the cholinesterase technique. J. Anat. (Lond.). 92:143-149.

2. Kobayashi, S., and T. Fujita. 1969. Fine structure of mammalian and avian pancreatic islets with special reference to $D$ cells and nervous elements. Z. Zellforsch. 100:340-363.

3. Miller, R. E. 1981. Pancreatic neuroendocrinology: peripheral neural mechanisms in the regulation of the islets of Langerhans. Endocrine Rev. 2:471-494.

4. Smith, P. H., and D. Porte, Jr. 1976. Neuropharmacology of the pancreatic islets. Annu. Rev. Pharmacol. Toxicol. 16:269-285.

5. Woods, S. C., and D. Porte, Jr. 1974. Neural control of the endocrine pancreas. Physiol. Rev. 54:596-619.

6. Bloom, S. R., and A. V. Edwards. 1981. Pancreatic endocrine responses to stimulation of the peripheral ends of the vagus nerves in conscious calves. J. Physiol. 315:31-41.

7. Frohman, L. A., E. Z. Ezdinli, and R. Javid. 1967. Effect of vagotomy and vagal stimulation on insulin secretion. Diabetes. 16:443448.

8. Lanciault, G., C. Bonama, and F. P. Brooks. 1973. Vagal stimu- 
lation, gastrin release, and acid secretion in anesthetized dogs. Am. J. Physiol. 225(3):546-552.

9. Fahrenkrug, J., H. Galbo, J. J. Holst, and O. B. Schaffalitzky de Muckadell. 1978. Influence of the autonomic nervous system on the release of vasoactive intestinal polypeptide from the porcine gastrointestinal tract. J. Physiol. 280:405-422.

10. Bergman, R. N., and R. E. Miller. 1973. Direct enhancement of insulin secretion by vagal stimulation of the isolated pancreas. Am. J. Physiol. 225(2):481-486.

11. Marliss, E. B., L. Girardier, J. Seydoux, C. B. Wollheim, Y. Kanazawa, L. Orci, A. E. Renold, and D. Porte, Jr. 1973. Glucagon release induced by pancreatic nerve stimulation in the dog. J. Clin. Invest. 52: 1246-1259.

12. Porte, D., Jr., L. Girardier, J. Seydoux, Y. Kanazawa, and J. Posternak. 1973. Neural regulation of insulin secretion in the dog. $J$. Clin. Invest. 52:210-214.

13. Holst, J. J., S. J. Jensen, S. Knuhtsen, and O. V. Nielsen. 1983. Autonomic nervous control of pancreatic somatostatin secretion. Am. J. Physiol. 245 (Endocrinol. Metab. 8):E542-E548.

14. Ahlman, B. H. J., G. M. Larson, C. T. Bombeck, and L. M. Nyhus. 1979. Origin of the adrenergic nerve fibers in the subdiaphragmatic vagus in the dog. Am. J. Surg. 137:116-122.

15. Muryobayashi, T. J., M. Fujiwara, and K. Shimamoto. 1968. Fluorescence histochemical demonstration of adrenergic nerve fibers in the vagus nerve of cats and dogs. Jpn. J. Pharmacol. 18:285-288.

16. Seino, S., H. Sakurai, Y. Seino, K. Tsuda, K. Tanigawa, H. Kuzuya, Y. Goto, and H. Imura. 1980. Starvation-induced changes of somatostatin, glucagon, and insulin secretion from the isolated perfused rat pancreas. Diabetes. 29:323-325.

17. Desbuquois, B., and G. D. Aurbach. 1971. Use of polyethylene glycol to separate free and antibody-bound hormones in radioimmunoassay. J. Clin. Endocrinol. Metab. 33:732-738.

18. Sakurai, H., and H. Imura. 1973. Radioimmunoassay of glucagon. Jpn. J. Nucl. Med. 10:135-136.

19. Imagawa, K., T. Hishino, S. Shin, S. Uehata, E. Hashimura, C. Yanaihara, and N. Yanaihara. 1979. Production of anti-glucagon sera with a C-terminal fragment of pancreatic glucagon. Endocr. Jpn. 26: 123-131.

20. Arimura, A., H. Sato, D. H. Coy, and A. V. Schally. 1975. Radioimmunoassay for GH-release inhibiting hormone. Proc. Soc. Exp. Biol. Med. 148:784-789.

21. Duncan, D. B. 1955. Multiple range multiple F tests. Biometrics. 11:1-42.

22. Uvnäs-Wallensten, K., and G. Nillson. 1978. A quantitative study of the insulin release induced by vagal stimulation in anesthetized cats. Acta Physiol. Scand. 102:137-142.

23. Holst, J. J., R. Gronholt, O. B. Schaffalitzky de Muckadel, and J. Fahrenkrug. 1981. Nervous control of pancreatic endocrine secretion in pigs. I. Insulin and glucagon responses to electrical stimulation of the vagus nerves. Acta Physiol. Scand. 111:1-7.

24. Schebalin, M., S. I. Said, and G. M. Makhlouf. 1977. Stimulation of insulin and glucagon secretion by vasoactive intestinal peptide. Am. J. Physiol. 232 (Endocrinol. Metab. Gastrointest. Physiol. 1):E197-E200.

25. Rehfeld, J. F., L.-I. Larsson, N. R. Goltermann, T. W. Schwartz, J. J. Holst, S. L. Jensen, and J. S. Morley. 1980. Neural regulation of pancreatic hormone secretion by the C-terminal tetrapeptide of CCK. Nature (Lond.). 284:33-38.

26. Dolais-Kitabgi, J., P. Kitabgi, P. Brazeau, and P. Freychet. 1979. Effect of neurotensin on insulin, glucagon, and somatostatin release from isolated pancreatic islets. Endocrinology. 105:256-260.

27. Hermansen, K. 1980. Effects of substance $P$ and other peptides on the release of somatostatin, insulin, and glucagon in vitro. Endocrinology. 107:256-261.

28. Green, I. C., D. Perrin, K. C. Pedley, R. D. G. Leslie, and D. A. Pyke. 1980. Effect of enkephalins and morphine on insulin secretion from isolated rat islets. Diabetologia. 19:158-161.

29. Larsson, L.-I., and J. F. Rehfeld. 1979. Peptidergic and adrenergic innervation of pancreatic ganglia. Scand. J. Gastroenterol. 14:433-437.

30. Nishi, S., Y. Seino, J. Takemura, H. Ishida, M. Seino, T. Chiba, C. Yanaihara, N. Yanaihara, and H. Imura. 1985. Vagal regulation of gastrin-releasing peptide (GRP), gastric somatostatin and gastrin secretion in vitro. Am. J. Physiol. 248 (Endocrinol. Metab.):E425-E431. 